\title{
Research on the current situation and Countermeasures of community sports in Pingxiang city under the background of national fitness
}

\author{
Jun Xiao, Wu Wen \\ Pingxiang University, Jiangxi 337055, China
}

\begin{abstract}
The development of community sports directly influence to the implementation of the national fitness project, in order to promote Pingxiang city community sports sustainable healthy development. Through the survey of the current community sports development situation, focused on the found the existing problems, and puts forward corresponding suggestions and countermeasures, improve the quality of community sports, play an effective role in the community sports in national fitness project advantages and functions.
\end{abstract}

Keywords: Community sports; National Fitness; current situation; countermeasure.

\section{Introduction}

The national fitness program is a major decision made by our country in order to carry out mass sports activities in order to further strengthen the people's health. In 2009, the state will further reform the national fitness program to the national fitness regulations, improve the national fitness program to the height of the whole society, fully embodies the national health of the national health. Because of its flexible organization form, rich content of activities, harmonious regional affection, convenient way of practice and effective fitness effect, community sports are attracting a large number of community residents. Therefore, it is necessary to investigate the development of community sports, find and improve the existing problems, further improve the management system of community sports, service system, play a role in community sports in the national fitness project.

\section{The research objects and methods}

\subsection{The research object}

The status quo of community sports in 13 communities in Pingxiang city.

\subsection{The research methods}

Documentation

Access to a large number of papers and papers on the status quo of community sports and development strategies.

Questionnaire survey

13 community residents in Pingxiang city by using random sampling method, 50 questionnaires were distributed, 650 questionnaires were distributed, 608 points were collected, the effective rate was $93.5 \%$, and 26 of them were distributed in 13 communities.

Expert interview method

Face-to-face interviews were conducted with the managers of community sports in 13 communities in Pingxiang.

Statistical method

The survey data were statistically processed.

\section{The research results and analysis}

\subsection{The status quo of community sports in Pingxiang City}

The members of the community sports

From to participate in community sports investigators found, the number of women significantly more than men, the ratio was $60.5 \%$ and $39.5 \%$, based on the segmented standard proposed by the United Nations age, the age of the participants in the elderly is given priority to, the proportion of participants over the age of $4581.25 \%$, and this age section staff work pressure, leisure time and other 
factors, most people to participate in sports population in other members of the more familiar, fixed partner.

The motivation and purpose of participating in community sports

Participation motivation is a kind of internal power that the residents of the community to participate in sports activities. Learned from the survey, community residents to participate in sports activities motivation is of them sorted in the first three is entertainment, enhance physical and mental health and adding a social layer, the proportion was $76.6 \%, 59.4 \%$ and $42.8 \%$, visible with the increase of leisure time, the increase of age, more people began pay attention to their own health problems. At the same time, we also want to see, although there are a lot of people like sports, but only $69.9 \%$ of the residents formed a habit, insist on long-term participation in physical activity.

The community sports activities in the form of

At present, Pingxiang city community residents to participate in sports present diversified development trend, before changing the fitness of single mode, from project selection to dance classes, exercise classes and sports mainly, the ratio was $65.5 \%, 48.4 \%$ and $44.4 \%$, which square dance, ballroom dance, Latin dance by community residents love. At the same time, there are many people like to participate in some sports and spend their leisure time.

The community sports venues

After investigation, the Pingxiang city community residents to participate in sports activities in the evening (45\%) and the morning (24\%), there are $15 \%$ of the residents are free to exercise, especially on the weekend, the time to participate in sports activities. The frequency of exercise is maintained at 2 times a week or more, accounting for about 85\%, the time for each exercise is 1 - 2 hours, $64 \%$. However, community residents to participate in sports activities in a non formal state, from table 3 can be seen in the square, Park (28.8\%) and district public sports venues (26.5\%) try to participate in sports activities, they carry out sports activities are also more spontaneous groups, there are some (15.8\%) residents choose to exercise in the charges clubs, and some buy sports equipment at home, which also led to $66.9 \%$ of the community's sports venues and facilities, can not meet the fitness needs.

\subsection{The sports consumption of community residents}

From table 4, table 5 of the statistical results can be seen, Pingxiang city community residents every year in the proportion of 200 to 500 yuan, also $10.4 \%$ of the total cost of spending more than 1000 yuan per year; they are mainly used in the payment of contributions and the purchase of sports apparel and other physical consumption, which need to pay a fee of $81.9 \%$ per year to certain institutions or organizations, more and more people are willing to invest in personal fitness.

\subsection{The management of community sports activities}

According to the survey of community residents, $46.4 \%$ of the residents of physical exercise in the place of sports participants themselves developed, belonging to the organization structure, and this type of sports content, time is relatively fixed, the person in charge is also more than a professor's coach. At the same time, community neighborhood committees or SF each year to provide the game rarely, most popular dance class almost no game, only the croquet, softball, gas volleyball ball will match a certain form of organization.

\subsection{The community residents' cognition of the whole nation fitness project}

The results show that: $91.4 \%$ of the residents know or part of the implementation of the full fitness project, only $8.6 \%$ of the community residents did not hear the national fitness activities. $85.4 \%$ of them believe that the implementation of the national fitness project can improve the physical quality of the people in different degrees, which may also be another reason for more and more community residents to participate in sports activities.

\subsection{The factors affecting the residents to participate in community sports}

From the investigation. The effect of Pingxiang City Community Residents in sports activities more reasons, objective aspects of the lack of sports facilities and community organization management of fatigue is the main reason, the ratio was $52.0 \%$ and $78.9 \%$, the subjective reasons of leisure time, sports hobbies and personal health condition is the main restricting factors, the ratio was 
$22.9 \%, 18.4 \%$ and $17.3 \%$. Obviously, it is very important to improve the enthusiasm of the community residents to participate in sports activities, and to create a certain exercise environment.

\subsection{The community sports service system}

At present, the management system of community sports in Pingxiang is a kind of government behavior, that is, under the leadership of the municipal government, the formation of the District, street, community service network management system of three levels. Through the investigation of 13 communities in Pingxiang City, all communities pay much attention to the development of community sports, and have a special administrative personnel to carry out the development of community sports, also developed a detailed rules and regulations. However, because of the limited number of administrative personnel in each community, the area within the district affairs, community stability and prosperity is the focus of the work, and community sports can only serve as a subsidiary of the nature of the work.

\section{The conclusions and recommendations}

\section{1 conclusions}

currently, Pingxiang City, the residents of community sports in the elderly, including women significantly more than men, to participate in community sports for leisure and health based, project selection to participate in the dance, aerobics and ball number, more in the community square, parks and community sports activities, and each exercise time in the 2 - 1 hours a large number of.

community residents in the physical consumption, the annual consumption in sports in the 200 500 yuan, up to $55.9 \%$ of the annual need to a certain percentage of organizations or organizations to pay a fee of $81.9 \%$.

community residents to participate in sports activities of the organization more than the spontaneous organization structure, $46.4 \%$ of the fitness activity is to develop the sports participants themselves, they rarely participate in community or street running organization sports competitions.

91.4\% of the residents know or part of the implementation of a comprehensive fitness program, including $85.4 \%$ of the implementation of the national fitness program can improve the quality of the people in different degrees.

the Pingxiang city community residents to participate in the sports activities of the many reasons, the objective aspect is lack of sports facilities and community organization and management is weak, the subjective aspect is leisure time and sports hobby.

current, Pingxiang city community sports service system is not perfect, the municipal government, street, community belonging to the lower level of government structure, the grass-roots community sports facilities, sports funding, etc. are not independent, fully rely on the higher level of special funds to the community sports publicity and guidance also lack of strength, leading to the development of community sports become the spontaneous behavior of the default state.

\section{2 recommendations}

To strengthen publicity and raise awareness. The healthy development of community sports must improve the community residents to the national fitness project, sports activities of the correct understanding, each community to increase the scientific fitness, improve the quality of life, build a harmonious community, the big propaganda efforts, with scientific means, to explore the physical condition, the changing law and the development trend, the importance of community sports, to provide appropriate services for community residents.

To give full play to the sports administrative functions of community street. At present, but by the possibility of community sports activities or sports competitions is very small, the influence is not enough, which requires community street office community sports development as a fixed thing for a long time to go, the community sports development into the assessment of the community.

To strengthen the training of community sports organization and management personnel and community instructors. At present, the weakest link in the community sports is the management personnel and the community instructors, they are the important power of our country's sports industry and the construction of the socialist spiritual civilization. The sports administrative 
departments must take on the training function of community sports cadres, social instructors, and constantly improve their professional quality and service capabilities, and strive to play their role in the development of community sports.

Fully mobilize and utilize the conditions of sports talents, resources and conditions in the community under the jurisdiction of the community. At present, the lack of sports facilities in the community is a common problem, on the one hand, to increase the construction of public sports facilities, on the other hand, it should take full advantage of the various units and schools in the area of the site and facilities, for the development of community sports to provide human and material support.

Broaden the sources of funding for community sports. In the current period, there have been some communities to get social organizations and individuals, but also to increase the funding of the community sports service through paid.

Advocates a variety of fitness, to carry out a variety of sports competitions, to create a community sports activities. Strongly support the development of family sports, make up for lack of fitness equipment, the organization of a certain community sports competition, to promote more people from watching sports to participate in the game to create the characteristics of the community sports activities, to create a certain advantage and brand, promote community sports better, faster development.

\section{References}

[1] WuSi Yan. Pingxiang community sports development present situation and countermeasure research [J]. Journal of pingxiang college, 2010 (1)

[2]ZhongbaoZhang. Investigation and development situation of community sports in tianjin countermeasures study [J]. Journal of tianjin sports college, 2003.18 (4)

[3]JianShe Yang community physical training present situation and the countermeasures study [J]. Journal of sports scientific research, 2006.27 (4)

[4] Tao Lv. Wuhu city community sports present situation and development countermeasure research [J]. Journal of military sports journals, institute for advanced study in 2006.25 (2) 